\title{
Sistem Pembayaran Kontrak kerja pembuatan Pagar Panel Beton (Studi Pada PG Kebon Agung Malang)
}

\author{
Arif Wahyudi \\ Fakultas Ekonomi Universitas Islam Balitar \\ Arif.wahyudisg999@gmail.com
}

Kata kunci

Sistem Informasi Akuntansi

Kontrak Kerja

Termin

\section{Keywords:}

Accounting Information System Employment Contract

Termin

ArifWahyudi (2020). System Pembayaran Kontrak Kerja Pembuatan Pagar Panel Beton (Studi pada PG Kebon Agung Malang). Akuntabilitas: Jurnal Ilmiah IlmuIlmu Ekonomi, 13(2), 39-49

\begin{abstract}
ABSTRAK
Penelitian ini dilakukan untuk menganalisa sistem pembayaran kontrak kerja dalam pembuatan pagar panel beton pada PG Kebon Agung Malang sehingga dapat memberikan informasi berupa data yang relevan, memiliki ketepatan waktu, akurat dan berguna bagi pemakainya. Pendekatan kualitatif digunakan dalam penelitian ini didasarkan pada data primer dengan memperoleh data langsung dari nara sumber dan menggunakan data skunder yang sumber datanya dokumen, catatan, serta pendukung lainnya. Hasil dari penelitian ini menjelaskan sistem informasi akuntansi dalam bentuk bagan alir sistem yang menjelaskan bagaimana alur sistem pembayaran kontrak kerja dalam pembuatan pagar panel beton di PG Kebon Agung dimulai dari $\mathrm{CV}$ menawarkan tender, setelah ditentukan pemenang tender pihak user memberikan surat pemenang tender sehingga CV pemenang tender bisa memulai pekerjaannya. Setelah pekerjaan selesai 92,5\%, CV membuat berita acara selesai pekerjaan sebagai bukti bahwa pihak CV telah menyelesaikan sebagian proyeknya dan mengajukan pembayaran dengan menyertakan invois, kuitansi, faktur pajak, berita acara, dan SPK kepada user untuk memperoleh blangko kasbon permintaan pembayaran termin pertama. Pembayaran termin kedua pihak CV membuat berita acara retensi (retention) sebagai terselesainya pekerjaan $7,5 \%$ yang diajukan untuk user beserta surat perjanjian kerja dan surat selesai pekerjaan SP.
\end{abstract}

\section{ABSTRACT}

This research was conducted to analyze the work contract payment system in the manufacture of concrete panel fences at PG Kebon Agung Malang so that it can provide information in the form of relevant data, have timeliness, are accurate and useful for the wearer. The qualitative approach used in this research is based on primary data by obtaining data directly from resource persons and using secondary data whose data sources are documents, notes, and other supporting data. The results of this study explain the accounting information system in the form of a system flow chart that explains how the flow of the work contract payment system in making concrete panel fences at Kebon Agung PG starts from $C V$ offering a tender, after being determined the tender winner, the user gives a tender winner letter so that the $C V$ is the winner of the tender. can start his work. After the work is $92.5 \%$ completed, CV makes a report of completion of work as evidence that $C V$ has completed part of its project and submits payment by including invoices, receipts, tax invoices, minutes, and SPK to the user to get a blank cash payment request for the first term. Payment of terms for both 


\section{PENDAHULUAN}

Perusahaan dibidang perdagangan, jasa atau industri kecil menengah baik bersekala lokal, nasional dan internasional harus mampu memanfatkan teknologi informasi yang sedang berkembang saat ini. Sistem informasi digunakan untuk memberikan informasi yang berupa data yang relevan, memiliki ketepatan waktu, akurat dan berguna bagi pemakainya sehingga dapat digunakan dalam pengambilan keputusan. Pencatatan data akuntansi diolah serta disajikan dalam laporan keuangan dapat membentuk suatu sistem dalam akuntasi.

Sistem informasi akuntansi merupakan suatu sistem berbasis computer didalamnya terdapat bagian-bagian yang saling berkaitan dan dibuat untuk merubah data-data akuntansi menjadi sebuah informasi yang akurat guna pengambilan keputusan untuk masa yang akan datang (Umar, 2017 :4). Kontrak kerja konstruksi merupakan perjanjian yang bermuatan bisnis dalam bentuk tertulis dimana kedua belah pihak yang terikat dalam melaksanakan tindakannya (Slamet, 2016:193). Selain kontrak kerja, kontraktor juga harus memperhatikan penjadwalan atau scheduling yang merupakan penentuan waktu yang dibutuhkan dalam menyelesaikan proyek secara keseluruhan dengan mempertimbangkan keterbatasanketerbatasan yang ada dalam pelaksanaanya.

Wiranata, Adnyana, dan Putiyana (2018:123) dalam penelitiannya menyatakan bahwa sistem pembayaran termin progres dana awal sangat menentukan keuntungan kontraktor selain dari segi penjadwalan konsisi EST memberikan keuntungan yang lebih besar dibandingkan dengan kondisi LST.

Sistem akuntansi mengatur arus transaksi maupun mengolahan data-data akuntansi sehingga menghasilkan informasi akuntansi yang tepat dan akurat, dan dapat digunakan bagi pihak ekstern dan intern perusahaan. Sistem merupakan suatu jaringan prosedur didalam organisasi yang saling berhubungan antara yang satu dengan yang lainnya dengan melaksanakan tugas dan fungsinya (Mulyadi, 2016:4), Sedangkan menurut Baridwan (2010:3) prosedur adalah suatu rangkaian kegiatan 
yang memiliki perlakuan kegiatan yang sama antara bagian yang satu dengan lainnya.

Menurut Mulyadi (2010:12) sistem informasi akuntansi memegang peran penting bagi perusahaan agar dapat mengendalikan perusahaan supaya berkembang dengan baik. Fungsi sistem informasi digunakan untuk mengelola usaha yang baru, membenahi bentuk sistem informasi yang sudah ada dan menyangkut tentang mutu, penyajian data atau bentuk-bentuk strukturnya dan membenahi pengendalian internal perusahaan.

Flowchart merupakan teknik analisis untuk menggambarkan beberapa aspek dari sistem informasi berupa simbol-simbol standar untuk menggambarkan proses transaksi perusahaan dan aliran data dengan jelas, ringkas, dan logis. (Romney dan Steinbart, 2012:75). Menurut Mulyadi (2016:25) flowchart lebih bermanfaat dibandingkan dengan uraian tertulis, karena menggambarkan sistem informasi secara menyeluruh, perubahan sistem dan pengidentifikasi kelemahankelemahannya akan lebih mudah diperbaiki

Kontrak kerja konstruksi atau construction Contract dikenal dengan perikatan tertulis antara pengguna jasa dengan penyedia jasa yang berbentuk kontrak (Slamet, 2016:192). Kontrak kerja konstruksi merupakan suatu perjanjian tertulis dimana pihak pengguna jasa dan penyedia jasa bidang kontruksi terdapat tindakan-tindakan bermuatan bisnis (Slamet, 2016:193). Sedangkan menurut Abidin (2010:4) kontrak kerja konstruksi adalah suatu negosiasi akan kombinasi aset yang berhubungan dengan rancangan teknologi dan berhubungan erat satu sama lain

Menurut Susanta (2007:247) termin merupakan cara pembayaran dengan perjanjian yang dikaitkan prestasi kemajuan pekerjaan atau sering disebut dengan bobot presentasi. Bobot presentasi pembayaran termin dilakukan pada pencapaian bobot pekerjaan dengan besaran 25\%, 25\%, 25\% 20\% dan 5\%. Pembayaran pencapaian bobot pekerjaan dengan besarnya 25\%,25\%,25\%, 20 dilakukan pada awal pekerjaan sampai pekerjaan selesai sedangkan sembayaran sebanyak $5 \%$ dilakukan setelah masa pemeliharaan selesai. Retensi merupakan penahanan uang oleh owner saat pembayaran. Pada umumnya retensi sebesar 5\% sebagai jaminan 
bahwa kontraktor telah melaksanakan keseluruhan pekerjaan dengan baik dan melakukan perbaikan apabila terjadi kerusakan

\section{METODE PENELITIAN}

Pendekatan kualitatif digunakan pada metode penelitian ini dengan berseumber pada data primer yang diperoleh langsung dan data sekunder yang diperoleh melalui dokumen, catatan, arsip-arsip serta pendukung lainnya. Sugiyono (2009:15), Pendekatan fenomenologi yang menekankan pada subjektivitas pengalaman hidup manusia, dengan mempelajari penampakan, pengalaman, cara kita mengalami sesuatu, dan makna dalam pengalaman kita (Kuswarno, 2009:22). Data dalam penelitian adalah kualitatif dan data kuantitatif. Data kualitatif berisikan semua bahan, keterangan data fakta-fakta yang tak dapat diukur dan dihitung tetapi hanya berwujud keterangan naratif, sedangkan data kuantitatif berisi keterangan atau fakta-fakta yang dapat diolah secara matematis (Prastowo. 2014:204).

Menurut Iskandar (2009:117) sumber data primer diperoleh dari hasil penelitian atau pengamatan dan data yang diperoleh diharapkan dapat memberikan informasi secara langsung kepada peneliti, sedangkan sumber data sekunder tidak langsung memberikan informasi data kepada peneliti, bisa berupa dokumen maupun data wawancara yang didapatkan dari orang lain.

Menurut sugiyono (2013:224), teknik pengumpulan data merupakan langkah yang paling strategis, karena tujuan utama dari penelitian adalah mendapatkan data. Data yang digunakan sebagian besar diperoleh dengan teknik pengumpulan sebagai berikut:

1) Observasi

Observasi merupakan suatu proses yang kompleks, suatu proses yang tersusun dari berbagai proses biologis dan psikologis. Sutrisno Hadi dalam (Sugiyono, 2013:145)

2) Wawancara

Menurut Esterberg dalam sugiyono (2013:231), wawancara merupakan proses Tanya jawab yang dilakukan oleh dua orang untuk mengumpulkan informasi dan kemudian menyimpulkan hasil dari kegiatan Tanya jawab tersebut. 


\section{3) Dokumentasi}

Menurut Sugiyono (2013:240, dokumen merupakan catatan peristiwa yang sudah berlalu. Dokumen bisa berbentuk tulisan, gambar, atau karya-karya monumental dari seorang.

Data yang terkumpul dari lapangan dilakukan analisa data dengan menyusunnya kedalam pola, ketegori, dan satuan dasar untuk mengetahui tema dan hipotesis kerja (Moleong, 2008:280). Data yang terkumpul melalui tekhnik pengumpulan data diatas kemudian dianalisa berdasarkan model pengumpulan data, reduksi data, penyajian data, dan menarik kesimpulan Miles dan Hubermen dalam prastowo (2014:243).

\section{PEMBAHASAN}

Kotrak kerja di PG Kebon Agung Malang merupakan tanggung jawab dari divisi pabrikasi. Divisi pabrikasi terdiri atas beberapa bagian yang disesuaikan dengan tugasnya masing-masing yaitu mengkoordinir seluruh kegiatan di lapangan mulai perbaikan peralatan, pembuatan permintaan dan penggunaan barang, dan membuat surat persetujuan permintaan barang.

Tujuan koordinir dari kegiatan lapangan tersebut yaitu untuk mempermudah dan memperlancar tugas yang diberikan kepada divisi pabrikasi. Selain hal tersebut, tugas bagian pabrikasi adalah mengkoordinir perbaikan. Data-data dari bagian kasubsi pabrikasi diajukan pada devisi pabrikasi yang terkait sehingga dapat diketahui apa saja yang perlu adanya perbaikan. Selanjutnya data di bawa pada bagian pabrikasi untuk diajukan ke bagian User. Setelah data lengkap, semua bagian akan dirapatkan untuk pengambilan keputusan dan nantinya akan diterbitkan undangan tender bagi beberapa $\mathrm{CV}$ guna perbandingan harga. CV yang terpilih tender akan menandatangani perjanjian kerja dengan kesepakatan yang sudah ditentukan serta semua hak dan kewajiban kedua belah pihak tercantum dalam perjanjian kerja tersebut.

Hasil penelitian sistem pembayaran kontrak kerja pada PG Kebon Agung Malang dapat dijelaskan sebagai berikut:

1) Prosedur pencatatan pembayaran kontrak kerja PG Kebon Agung Kota Malang dimulai dari bagian CV dengan menawarkan tender melalui surat 
penawaran tender kepada pihak PG di bagian User. Selanjutnya bagian user melakukan negosiasi tender dari CV. Setelah ditentukan pemenang tender, pihak user memberikan surat pemenang tender kepada $\mathrm{CV}$. Dan $\mathrm{CV}$ bisa memulai pekerjaannya.

2) Setelah pekerjaan selesai $92,5 \%, \mathrm{CV}$ membuat berita acara selesai pekerjaan termin pertama sebagai bukti bahwa pihak CV telah menyelesaikan sebagian proyeknya. Kemudian pihak CV memberikan BASP kepada User besertakan Surat Perjanjian Kerja (SPK) dan Surat Perintah Kerja (SPP).

3) Setelah itu, bagian User memeriksa berkas tersebut apabila semua sesuai maka user melakukan ACC serta memberikan semua berkas yang sudah sesuai kepada CV dan jika belum sesuai semua berkas tersebut dikembalikan pada $C V$.

4) Berdasarkan berkas yang telah disetujui oleh User, selanjutnya CV mengajukan pembayaran dengan menyertakan invois, kuitansi, faktur pajak, berita acara, dan SPK kepada user.

5) User menerima berkas dari pihak $C V$, setelah semua berkas lengkap, user membuatkan blangko kasbon permintaan pembayaran termin pertama yang kemudian diserahkan pada bagian akunting untuk diverifikasi.

6) Setelah diverifikasi bagian akunting membuatkan kasbon yang berupa bukti pengeluaran kas/bank untuk diserahkan pada bagian kasir.

7) Bagian kasir setelah menerima bukti pengeluaran kas/bank melakukan pembayaran termin satu dengan menyerahkan Bukti Pembayaran beserta uang kepada CV.

8) Setelah menerima pembayaran termin pertama pihak CV membuat berita retensi 7,5\% yang diajukan untuk user beserta Surat Perjanjian Kerja (SPK) dan Surat Selesai Pekerjaan (SSP) untuk pembayaran termin ke dua.

9) Berdasarkan berkas tersebut, bagian User memeriksa berkas, apabila semua sudah sesuai maka user melakukan ACC serta memberikan semua berkas yang sudah sesuai kepada CV dan jika belum sesuai semua berkas tersebut dikembalikan pada CV. 
10) Berdasarkan berkas yang telah disetujui oleh User, selanjutnya CV mengajukan pembayaran dengan menyertakan invois, kuitansi, dan berita acara kepada user.

11) Setelah semua data lengkap, user membuatkan blangko kasbon permintaan pembayaran termin kedua yang kemudian diserahkan pada bagian akunting untuk diverifikasi.

12) Setelah diverifikasi bagian akunting membuatkan kasbon yang berupa bukti pengeluaran kas/bank untuk diserahkan pada bagian kasir.

13) Bagian kasir setelah menerima bukti pengeluaran kas/bank melakukan pembayaran termin satu dengan menyerahkan Bukti Pembayaran beserta uang kepada CV. 

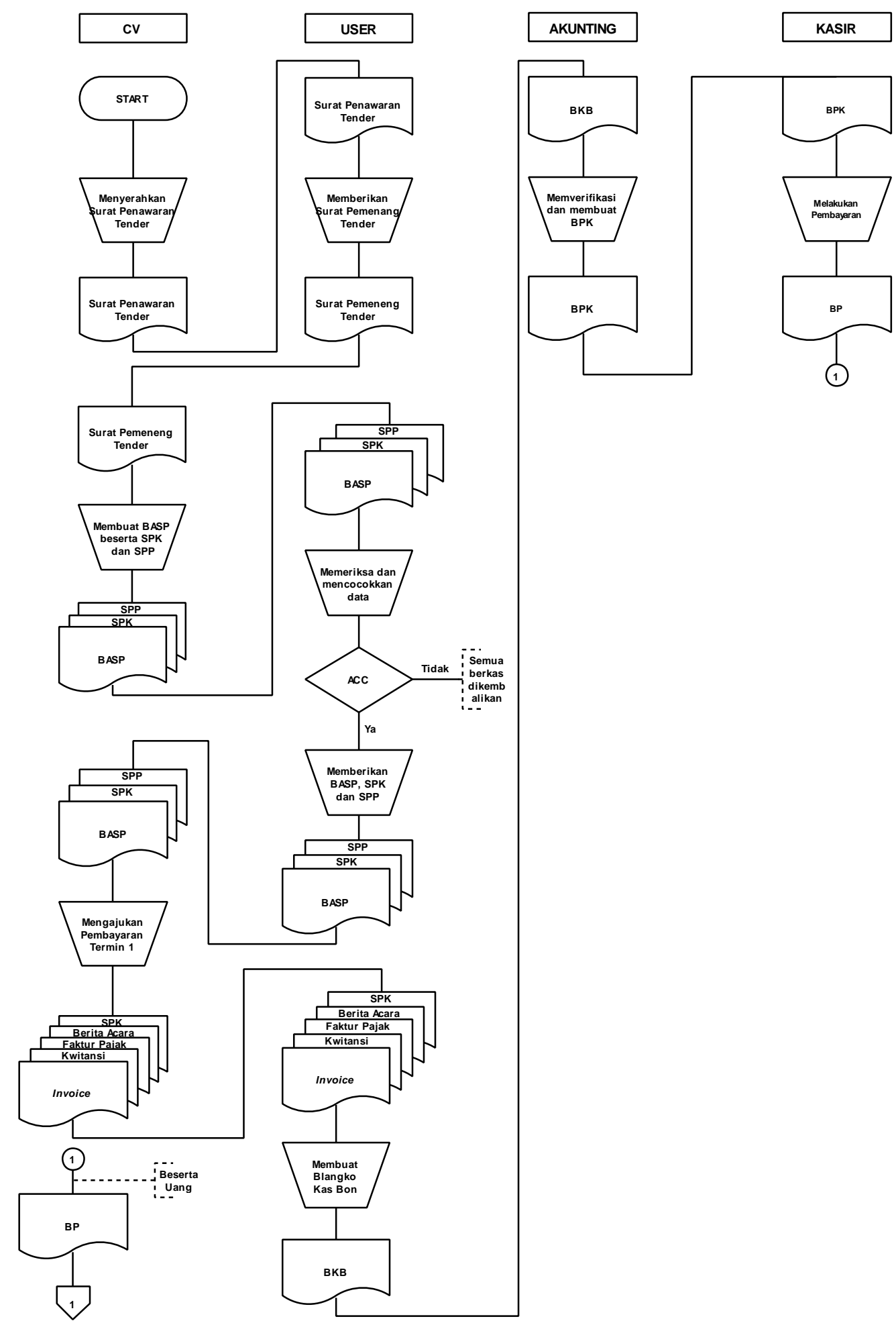


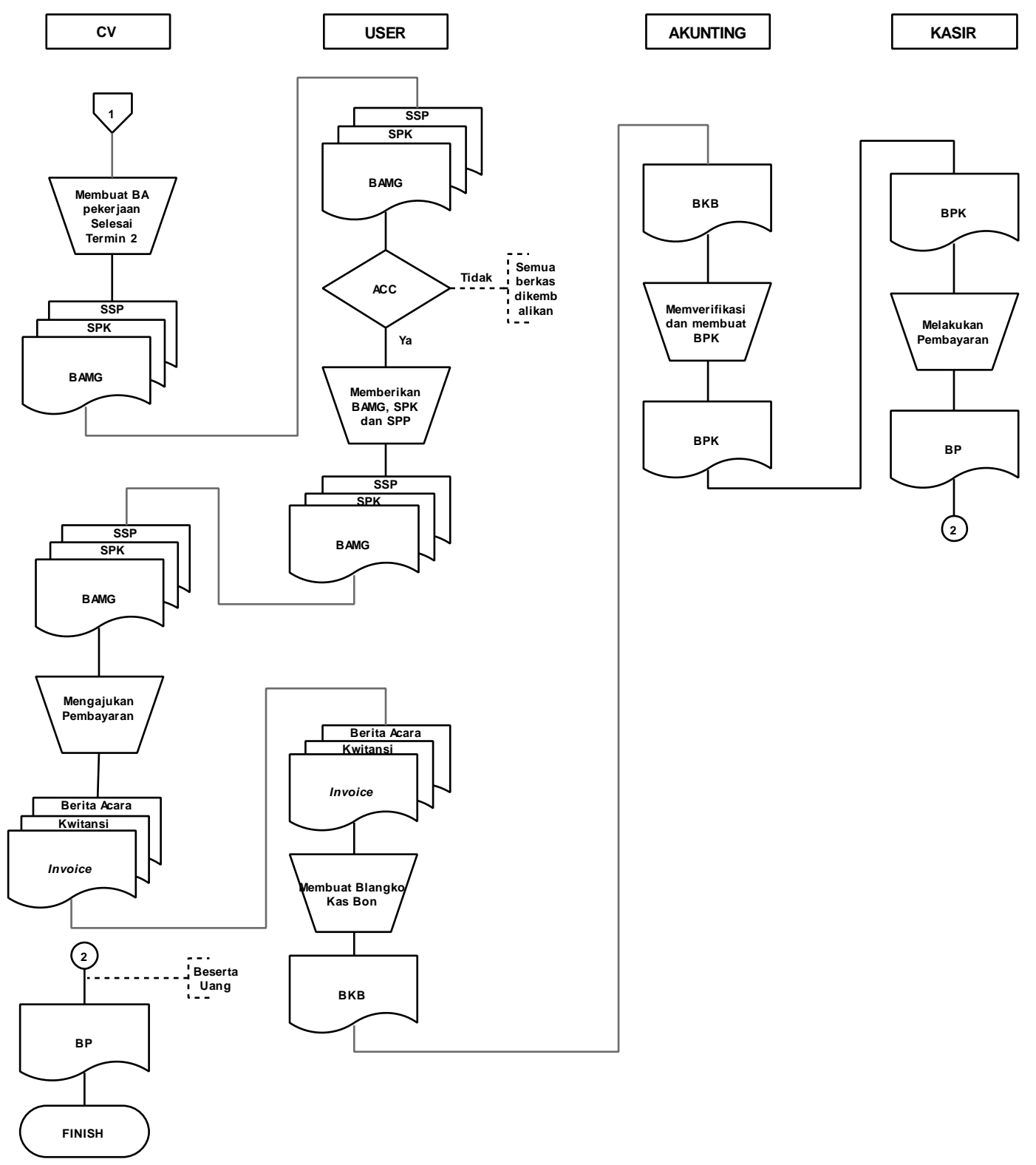

Hasil penelitian diatas bahwa sistem pembayaran kontrak pembuatan pagar panel beton di PG Kebon Agung hanya menggunakan dua termin yaitu : termin pertama $92,5 \%$ setelah pekerjaan selesai dan termin kedua 7,5\% sebagai retensi atas hasil pekerjaan. CV yang berhak melaksanakan pekerjaan merupakan CV sebagai pemenang tender yang sebelumnya telah melakukan penawaran tender kepada pihak PG di bagian user, setelah berkas pengajuan termin pertama dan kedua lengkap serta telah terselesainya pekerjaan, $\mathrm{CV}$ dapat menerima pembayaran kas berupa uang tunai yang diberikan oleh PG pada bagian kasir. 


\section{KESIMPULAN}

Sistem pembayaran kontrak kerja biasanya dilakukan oleh perusahaan jasa kontruksi yang sistem pembayarannya menggunakan termin, dimana pembayarannya secara bertahap sesuai dengan dokumen perjanjian yang telah ditetapkan oleh pihak-pihak yang terkait. Sistem pembayaran kontrak pembuatan pagar panel beton di PG Kebon Agung hanya menggunakan dua termin yaitu : termin pertama 92,5\% setelah pekerjaan selesai dan termin kedua 7,5\% sebagai retensi atas hasil pekerjaan dan pembayaran dari kontrak kerja tersebut dapat dilakukan jika berkas pengajuan termin pertama dan kedua lengkap serta telah terselesainya pekerjaan, $\mathrm{CV}$ dapat menerima pembayaran kas berupa uang tunai yang diberikan oleh PG pada bagian kasir.

\section{DAFTAR PUSTAKA}

Agus Mulyanto. 2009. Sistem Infomasi Konsep dan Aplikasi. Yogyakarta. Pustaka Belajar

Anwar Sanusi. 2011. Metodologi Penelitian Bisnis. . Jakarta Selatan. Salemba Empat Arikunto, S. 2016. Prosedur Penelitian Suatu Pendekatan Praktik. Jakarta. Rineka Cipta

Baridwan, Zaki. 2008. Sistem Akutansi Penyusunan Prosedur dan Metode. Yogyakarta: BPFE

Baridwan, Zaki. 2010. Sistem Akuntansi. Edisi Kelima. Yogyakarta: BPFE

Bodnar. 2010. Accounting Information System. Yogyakarta. ANDI

Diana, Anastasia., Lilis Setiawati. 2011. Sistem Informasi Akuntansi. Perancangan, Proses, dan Penerapan. Edisi 1. Yogyakarta: ANDI

H.M Jogiyanto. 2010. Analisis dan Desain Sistem Informasi. Yogyakarta. Andi Onset

Iskandar. 2009. Metodologi Penelitian Kualitatif. Jakarta. GP Press

Jogiyanto Hartono. 2009. Analisis dan Sistem Informasi. Yogyakarta. ANDI

Marshal B. Romney, dan Paul John Stein Bart. 2015. Sistem Informasi Akuntansi.Edisi 13. Jakarta Selatan. Salemba Empat

Mursyidi. 2010. Akuntansi Dasar. Bogor: Ghalia Indonesia.

Mulyadi. 2016. Sistem Akuntansi. Edisi 4. Jakarta. Salemba Empat

Romney, Marshal B., dan Paul John Steinbert. 2014. Accounting Information System, 13 th ed. England. Pearson Educational Limited. 

(Jakarta: Sinar Grafika, 2004:3)

Soemarso S.R. 2004. Akuntansi Suatu Pengantar. Jakarta: Salemba Empat

Subekti “Hukum Perjanjian,” cet. XII (Jakarta: PT. Intermasa, 1990:1)

Sugiyono. 2010. Metode Penelitian Kuantitatif Kualitatif dan R\&D. Bandung. Alfabeta

Sugiyono. 2014. Memahami Penelitian Kualitatif. Bandung. Alfabeta

Susanta.2007.Panduan Lengkap Membangun Rumah. Cimanggis Depok.Penebar Swadata.

Yakub. 2012. Pengantar Sistem Informasi. Yogyakarta. Graha Ilmu 